\section{Comparison of Seed-quality Indices Resulting from Single-seed Electroconductivity Measurements}

\author{
K.G.V. Davidson and F.D. Moore, III \\ Department of Horticulture, Colorado State University, Fort Collins, \\ CO 80523
}

E.E. Roos

U.S. Department of Agriculture, Agricultural Research Service, National Seed Storage Laboratory, 1111 South Mason Street, Fort Collins, CO 80521-4500

S. Nath

Department of Horticulture, Colorado State University, Fort Collins, CO 80523

S. Sowa

U.S. Department of Agriculture, Agricultural Research Service, National Seed Storage Laboratory, 1111 South Mason Street, Fort Collins, CO 80521-4500

Additional index words. Zea mays, electrolyte leakage, initial slope, internal slope, Richards function, seed germination

\begin{abstract}
Five seed-quality indices based on individual seed electrolyte leakage tests were evaluated. Zea mays L. seeds were soaked for 6 hours, and individual seed leachate conductivity values were obtained. A total of 100 cells were scanned, one seed per cell, at 5-minute intervals for the first 30 minutes, followed by 15-minute intervals for the remaining 330 minutes. Seeds were allowed to dry for 5 to 7 days at room temperature and then were tested for germinability at $25 \mathrm{C}$ for 7 days. Radicle lengths were measured after 72 hours. The Richards function was fitted to cumulative frequency distributions of $\mu$ Amps to obtain internal slope (IS), mean $\mu \mathrm{Amp}$, and median $\mu$ Amp values for each scan. Initial leach rate (ILR) was estimated after fitting hyperbolic functions to $\mu$ Amp vs. soak time data. Average leach rate (ALR) was also derived from fitting the Richards function to $\mu$ Amp vs. soak time data. Linear regression of seed quality on IS, mean, and median $\mu$ Amp values after 5 hours of imbibition yielded $r^{2}$ values of $0.91,0.81$, and 0.86 for predicting viability and $0.56,0.46,0.52$ for predicting radicle length. Thus, IS was the best seed quality predictor, followed closely by median and mean $\mu$ Amp values. ILR and ALR were not correlated with seed quality.
\end{abstract}

Seed genebanks often have limited quantities of seed available for testing; therefore, it is important to develop a method to test a seed sample without destroying it. Determining seed viability traditionally has involved a standardized germination test, which is obviously destructive to seed and labor intensive. Electroconductivity (EC) measurements of singleseed leachate solutions could lead to the replacement of the standard germination test if the measurements could be taken early during imbibition, which, in turn, would lead to the

Received for publication 28 Oct. 1993. Accepted for publication 28 May 1994. This research was funded by the International Board for Plant Genetic Resources and the Colorado Agricultural Expt. Station, project 721 . Use of trade names does not imply endorsement of the products named nor criticism of similar ones not named. We appreciate the technical assistance of Laura Ledbetter and Gareth Redgrave. This paper is from a thesis submitted by K.G.V.D. in partial fulfillment of the MS requirements. The cost of publishing this paper was defrayed in part by the payment of page charges. Under postal regulations, this paper therefore must be hereby marked advertisement solely to indicate this fact. development of nondestructive testing methods for seed quality (i.e., viability and vigor determination).

Leachate EC was first proposed as a seed quality test more than 25 years ago (Matthews and Bradnock, 1968); such tests are rapid and simple and, as such, provide the seed industry with an alternative to tests based on germination, which require 7 to 42 days to complete. One of the most strongly correlated indicators of seed vigor and germinability is the leakage of intracellular substances from imbibing seeds (Duke et al., 1983). Nonviable tissue leaks electrolytes, producing high leachate EC values (Matthews and Bradnock, 1968). Low EC values are associated with high-quality seed (Keys, 1982; Parrish and Leopold, 1978); high germination rates; and vigorous, uniform seedling growth (Steere et al., 1981). Seed leachate $\mathrm{EC}$ is a good indicator of seed deterioration (Ching and Schoolcraft, 1968). However, as currently performed, EC tests are similar to the standard germination test because they destroy seeds. Earlier approaches using EC involved bulked seed samples or data partitioning associated with individual seed con- ductivities and long soaks of $\leq 24$ hours for maize (Bondie et al., 1979; Furman et al., 1987; Matthews and Bradnock, 1968; McDonald and Wilson, 1980; Pandy, 1988).

Beginning in 1981, EC measurements of individual seed leachates became practical, and data were summarized in a manner to predict germination (Steere et al., 1981) based on partitioning of $\mu$ Amp values from a seed analyzer that almost simultaneously measured EC values of 100-seed leachate solutions. A partition value, $\mu$ Amps, was determined empirically, and it was assumed that each seed with a value above the partition value was dead, and those with a value below were alive. The seed analyzer measured the soak-water current-carrying capacity ( $\mu$ Amps per seed), which was highly correlated with EC in $\mu$ mhos perseed $\left(1 \mu \mathrm{mho} / \mathrm{cm}=10^{-3} \mathrm{dS} \cdot \mathrm{m}^{-1}\right)($ McDonald and Wilson, 1979). Bulk EC and optimized partitioning were equally effective in predicting germination percentage for $s h$ - 2 corn (Wilson, 1992). The single-seed approach permits the formation of a cumulative $\mu$ Amp frequency distribution (CFD).

An important advantage measuring singleseed leachate ECs vs. bulk ECs is that a few severely deteriorated seeds do not affect the results as much as in the bulk test. Severely deteriorated seeds may release more electrolytes than those just at the point of losing viability (Steere et al., 1981). EC measurements of single-seed leachates reflect the extent of each seed's membrane disorganization by measuring the amount of electrolytes released into the soak water (Pandey, 1988). Interestingly, single-seed leachate analysis using a seed analyzer is more accurate at low ionic concentrations $(\mathrm{KCl}<1 \mathrm{~mm})$ than the bulk method (Hepburn et al., 1984).

Population distribution graphs of current values ( $\mu \mathrm{Amps})$ are good visual indicators of seed lot quality (Bondie et al., 1979). Moore et al. (1988) suggested that the shape of the $\mu$ Amps CFD provided an estimate of seed lot quality. CFD slope steepness reflects the width of the $\mu$ Amp value distribution. The more horizontal the slope, the greater the seedto-seed variability and the poorer the seed lot quality. Thus, the variability within the population of 100 seeds is indicated by shape of the CFD independent of the CFD's location on the $\mu$ Amp axis. Modeling the CFD [i.e., fitting a function to cumulative frequency $(n=100$ seeds)] vs. $\mu$ Amp data permits taking the derivative, which, when evaluated at its maximum, yields a single index of seed quality based on curve shape.

The Richards function (Richards, 1959) has been used to model leaf growth (Causton et al., 1978), seed germination (Berry et al., 1988), and single-seed leachate ECs (Moore et al., 1988). It is nonlinear in two of its four parameters, and it is not only asymptotic but flexible enough to fit normally and nonnormally distributed data. Current value ( $\mu \mathrm{Amps})$ distributions have been reported to be nonnormal (Wilson, 1992), indicating appropriate application of the function.

A noncentral tendency measure based on 100 individual seed leachate conductivities, 
called internal slope (IS), was developed to describe levels of seed deterioration. IS (Moore et al., 1988) can be considered a secondary parameter (Causton et al., 1978) of the Richards function; it is the slope of a line tangent to the inflection point of the sigmoidal CFD curve. The tangent line is virtually the same as the linear segment of the S-shaped CFD, thus indicating the spread of observations over the $\mu$ Amp axis. Therefore, IS becomes a sensitive tool that reflects the shape of the CFD of $\mu$ Amps. IS has the potential to predict seed quality, and the reciprocal of IS measures individual seed-to-seed variability in ion leakage (Moore et al., 1988) - it is determined numerically as the derivative of the curvefitting function at the inflection point of the curve where cumulative frequency is a function of cumulative $\mu$ Amps given a total 100 seed frequency. The shape of CFD and its corresponding numerical evaluation are independent of any central tendency measure, such as the mean, median, or mode.

Our goal was to investigate possible predictors of maize seed quality based on EC values of 100 individual seed leachates. The objective was to compare IS with other secondary parameters, initial leach rate, average leach rate, and frequency distribution mean and median for evaluating quality of maize seed lots.

\section{Materials and Methods}

We used two high-quality maize seed lots, [B73 x LH51, lots 88-1d (dryland) and 88-2i (irrigated)]. The irrigated lot showed some deterioration over the dryland lot. Both were artificially aged (Bruggink, 1989) by equilibrating seeds from each lot en mass to $\approx 16 \%$ moisture (dry weight basis) over a saturated $\mathrm{NaCl}$ solution, equivalent to $75 \%$ relative humidity (RH) at $20 \pm 1 \mathrm{C}\left(\mathrm{O}^{\prime}\right.$ Brien, 1948), for 16 and 20 days for lots $88-2 \mathrm{i}$ and $88-1 \mathrm{~d}$, respectively. Afterwards, 110-seed allocates were sealed in individual, plastic, foil laminated bags and aged for $120 \mathrm{~h}$ at $45 \mathrm{C}$ in a convection oven.

One-hundred seeds per tray were soaked for $6 \mathrm{~h}$ with $2 \mathrm{ml}$ deionized water per $4 \mathrm{ml}$ cell. Scans, consisting of 100 individual EC readings, were obtained at 5-min intervals for the first $30 \mathrm{~min}$, followed by 15 -min intervals for the remaining $330 \mathrm{~min}$. A total of 29 scans were made during the soak period, constituting one test. Conductivity of seed leachate was measured in $\mu \mathrm{Amps}$ per seed by a seed analyzer (model 1000B; Neogen Food Technolgy Corp., Lansing, Mich.) at a $1 \mathrm{~V}$ setting. Microampere data were automatically collected at the predesignated times and stored in a computer file for later analysis. The seeds were removed with forceps and placed into specially designed drying trays that permitted movement of air around each seed. The trays were placed on the laboratory bench at $\approx 23 \mathrm{C}$ and $20 \%$ RH for 5 to 7 days, at which time the initial moisture content (MC) was reached. Concurrent soaking of another seed batch for $\mathrm{MC}$ monitoring was used to infer when the EC sample had attained its original moisture level.

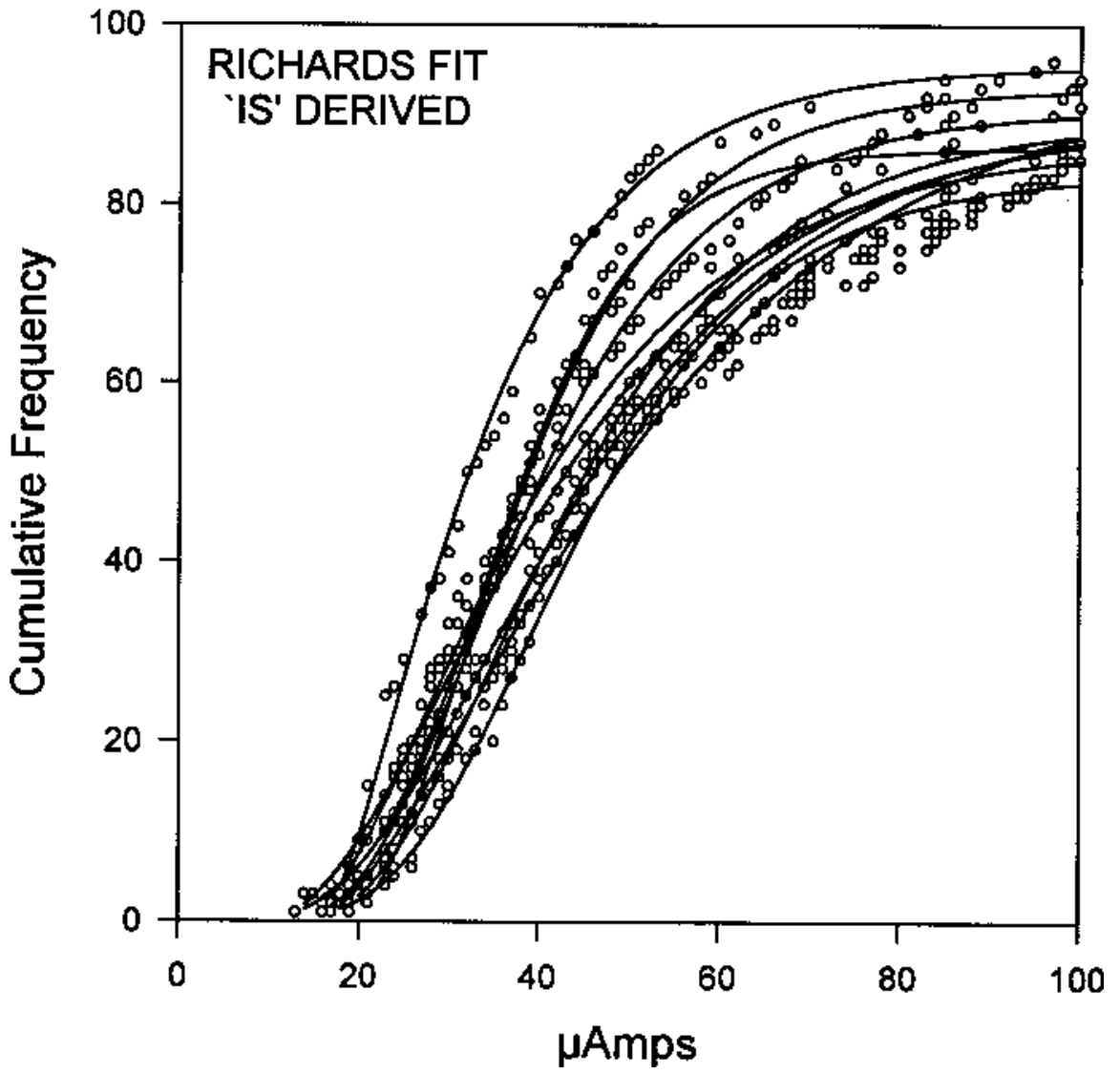

Fig. 1. Measured curves (symbols) were fitted by the Richards function (lines). Internal slope (IS) values, one per electroconductivity test (i.e., line), were derived after soaking maize seeds for $5 \mathrm{~h}$.

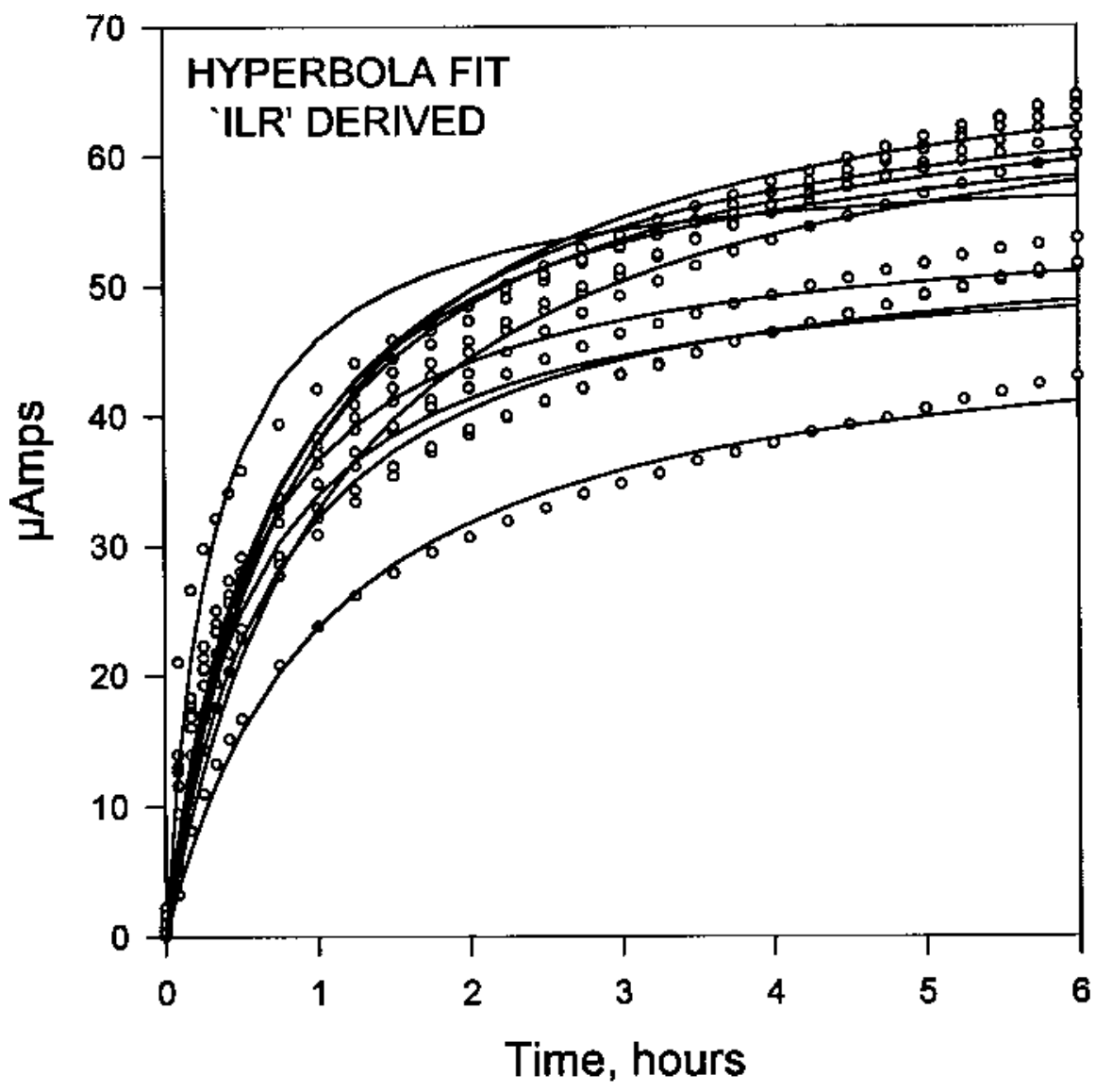

Fig. 2. Measured curves (symbols) were fitted by rectangular hyperbolic function (lines). Initial leach rates (ILR), one per electroconductivity test with maize seed (i.e., line), were derived. 
MC was determined by oven-drying the MC sample for $24 \mathrm{~h}$ at $105 \mathrm{C}$. When the seeds reached the original $\mathrm{MC}$, the EC sample was germinated using the rolled-paper-towel method (Association of Official Seed Analysts, 1988). Simultaneously, 100 nonsoaked seeds were germinated to serve as a control for the hydrated-dehydrated seeds used for EC tests. After $72 \mathrm{~h}$, the seeds were removed long enough to measure radicle lengths, then returned to complete the required 7 days of germination. Seed quality was measured as percent germination and radicle length. Each test consisted of 100 soaked seeds per EC sample, 100 nonsoaked (control) seeds for a paired germination test, and 10 seeds for MC determination. Ten tests, five from each aged seed lot, were conducted for each of the five candidate predictors of maize seed quality.

A form of the Richards function, where $\mathrm{CF}$

$$
\begin{aligned}
\log _{\mathrm{e}} \mathrm{CF}= & \log _{\mathrm{e}} \mathrm{A}-(1 / \mathrm{N}) \log _{\mathrm{e}}[1 \pm \exp \\
& (\mathrm{b}-\mathrm{k} \mu \mathrm{Amps})]
\end{aligned}
$$

represents the cumulative frequency and $\mathrm{A}, \mathrm{N}$, $\mathrm{b}$, and $\mathrm{k}$ are constants, is a generalization of the logistic function and fits data sets that exhibit a limit (i.e., an asymptote). A unique and important advantage of the fitting program (Nath et al., 1990) is that initial parameter values are not required; the program initializes its own (Causton, 1969), whereas other nonlinear curve fitting programs do not. The Richards function was fitted to the $\mu \mathrm{Amp}$ CFDs to derive IS, the mean and median $\mu$ Amp values for each of the 29 scan times for each test. The IS index at $5 \mathrm{~h}$ was chosen for evaluation based on the time course for IS stabilization (data not shown).

The two-characteristic rectangular hyperbolic function (Johnson, 1987) was fitted to $\mu$ Amp vs. soak time data to obtain the initial leach rate (ILR),

$\mu \mathrm{Amps}=\mathrm{At} / \mathrm{Am}+\mathrm{t}$

where A represents the asymptotic maximum leach rate in terms of $\mu \mathrm{Amps}$, and $\mathrm{t}$ is soak time. The initial slope $(1 / \mathrm{m})$, also the maximum slope, was calculated at soak time zero (Johnson, 1987). The Richards function program (Nath et al., 1993) also was fitted to $\mu A m p$ vs. soak time data to derive the average leach rate (ALR) over the entire soak period. This represents an average absolute rate (Causton et al., 1978), in this case an average leakage rate.

Germination and radicle length were regressed on each of the five candidate indices of maize seed quality. Analyses of variance (ANOVA) were performed on each of the five linear regressions.

\section{Results and Discussion}

Artificially aging the two seed lot populations provided several levels of viability, ranging from $0 \%$ to $89 \%$ germination. Even though the aging method used was a modification of the controlled deterioration method (Bruggink, 1989), variation in germination percentage

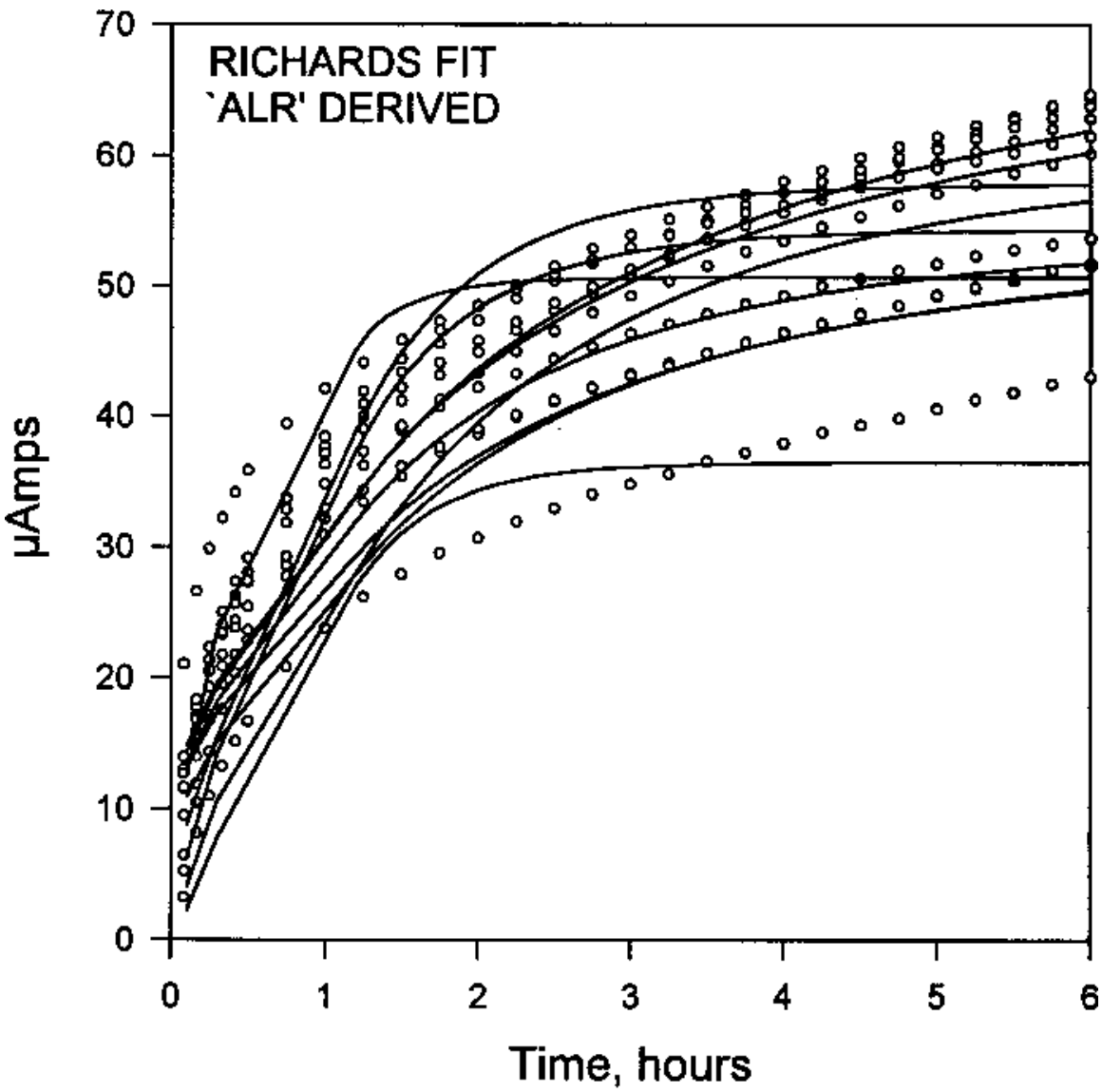

Fig. 3. Measured curves (symbols) were fitted by the Richards function (lines). Average leach rate (ALR) values for maize seed, one per electroconductivity test (i.e., line), were derived.

among samples still occurred. The broad range in seed quality probably was caused by the differences in seed MC before aging or the position in the convection oven that was used for aging. Radicle lengths ranged from $0 \mathrm{~mm}$ to $28 \mathrm{~mm}$. Radicles of the EC samples grew faster and were longer than the nonsoaked controls, suggesting invigoration of the former (data not shown). Root mean square error (RMSE) was used to compare the experimental precision with which the function of $\mu \mathrm{Amps}$ and the two functions of soak time modeled the 88-1d seed lot and the $88-2 \mathrm{i}$ seed lot. Both average RMSEs were 2.27; thus, random experimental errors were the same for the two seed lots.

The Richards function was used to derive IS from primary data (Fig. 1), and the rectangular hyperbolic function was used to derive ILR (Fig. 2). The Richards function also was used to derive ALR (Fig. 3); it is termed flexible because it fits data patterns from hyperbolic to sigmoidal (France and Thornley, 1984). Furthermore, the hyperbolic function provides a characteristic $m$, the reciprocal of which represents IS, one of our candidate indices. Because observations were not repeated, the three graphs (Figs. 1-3) visually support the nonlinear regressions. Each of these three models is nonlinear in one or more of its parameters, and because each of the indices derived from the models involves different parameters, significance testing between the models is inappropriate.

Inflection point locations (Fig. 1) for the 10

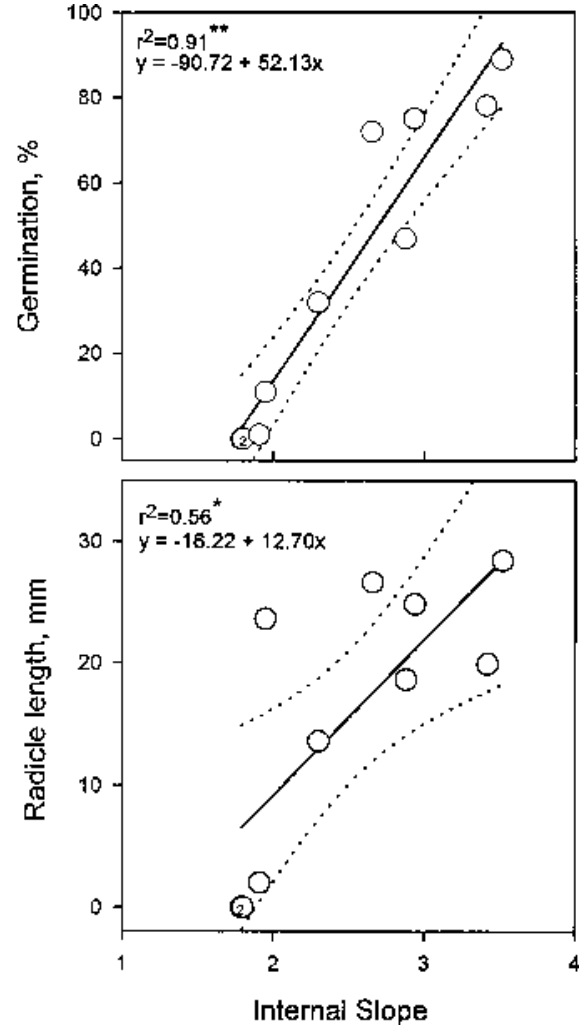

Fig. 4. Prediction of maize germination and radicle length by internal slope (IS) at $5 \mathrm{~h}$ of imbibition; 95\% confidence bands. ${ }^{*}{ }^{* *}$ Significant at $P \leq$ 0.05 and 0.01 , respectively. 
tests ranged from 24 to $39 \mu$ Amps. The best predictor of maize seed quality was IS, with a positive $r^{2}$ of 0.91 for percent germination; yet IS accounted for only $56 \%$ of the variation in radicle length (Fig. 4). Seed lot had no effect on the index as a predictor of seed quality (Table 1). The Richards program (Nath et al., 1990) used to form the $\mu$ Amps CFD derives the IS index at every scan time. IS can accurately predict seed quality because it embodies the shape of the $\mu$ Amps CFD (Moore et al., 1988) at any instant during the soak period.

Mean and median $\mu$ Amp values of 100 individual maize seed leachates after 5-h imbibition represent measures of central tendency of the frequency distribution. Figure 5 shows that $81 \%$ of the variation in percent germination is accounted for using the mean $46 \%$ of the variation in radicle length. Seed lot had no effect on the mean as a seed quality predictor (Table 2). Germination percentage and radicle length were inversely related to the mean $\mu$ Amp value after 5 -h imbibition (Fig. $\mu$ Amp value, yet the mean accounted for only

5). This result was expected because the EC test is based on the amount of seed deterioration being proportional to loss of cell membrane integrity (Matthews and Bradnock, 1968; Powell, 1986). McDonald and Wilson (1980) demonstrated that the seed analyzer monitored changes in soybean [Glycine max. (L.) Merr.] seed quality as a result of mechanical damage and accelerated aging. As expected, mean $\mu$ Amp values from single-seed $\mathrm{EC}$ values were close to those achieved using the bulk method (Wilson, 1992). The bulk method and location distribution measures cannot account for seed-to-seed variability or population distribution within a seed lot (Mullet and Wilkinson, 1979).

The median $\mu$ Amp value is also a measure of central tendency; but unlike the mean, it is not influenced as much by extreme values as is the distribution mean. The inverse relationship between percent germination and radicle length to the median value provided a slightly better prediction capacity than the mean, accounting for $86 \%$ of the variability in germina-

Table 1. Analysis of variance for linear regression of the internal slope (IS) index at 5 -h imbibition on percent germination and radicle length.

\begin{tabular}{lcccc}
\hline \hline Source & df & Mean square & F statistic & Probability \\
\hline & & \% Germination & & \\
IS & 1 & 10687 & 75.79 & 0.00 \\
Seed lot & 1 & 69.67 & 0.49 & 0.51 \\
Seed lot $\times$ IS & 1 & 163.94 & 1.16 & \\
Error & 6 & 141.01 & & 0.32 \\
Total & 9 & & & 0.02 \\
& & Radicle length & & 0.18 \\
IS & 1 & 634.62 & 10.45 & \\
Seed lot & 1 & 1.22 & 0.02 & 0.00 \\
Seed lot $\times$ IS & 1 & 136.35 & 2.25 & \\
Error & 6 & 60.71 & & \\
Total & 9 & \% Germination & & \\
& & 10686.85 & 79.19 & \\
Model & 1 & 134.96 & & \\
Error & 8 & & & \\
Total & 9 & Radicle length & & \\
& & 634.62 & & \\
Model & 1 & 62.72 & & \\
Error & 8 & & & \\
Total & 9 & &
\end{tabular}

Table 2. Analysis of variance for linear regression of the mean $\mu$ Amp value at 5-h imbibition on percent germination and radicle length.

\begin{tabular}{lcccc}
\hline \hline Source & df & Mean square & F statistic & Probability \\
\hline & & \% Germination & & \\
Mean $\mu$ Amps & 1 & 9551.33 & 32.80 & 0.00 \\
Seed lot & 1 & 137.14 & 0.47 & 0.52 \\
Seed lot $\times$ mean & 1 & 331.04 & 1.14 & \\
Error & 6 & 291.16 & & \\
Total & 9 & & & 0.05 \\
& & Radicle length & & 0.96 \\
Mean $\mu$ Amps & 1 & 517.38 & 6.33 & 0.26 \\
Seed lot & 1 & 0.23 & 0.00 & \\
Seed lot $\times$ mean & 1 & 128.13 & 1.57 & \\
Error & 6 & 81.78 & & \\
Total & 9 & \% Germination & & \\
& & 9551.33 & 34.49 & \\
Model & 1 & 276.89 & & \\
Error & 8 & & & \\
Total & 9 & Radicle length & & \\
& & 517.38 & & \\
Model & 1 & 77.38 & & \\
Error & 8 & & & \\
Total & 9 & &
\end{tabular}

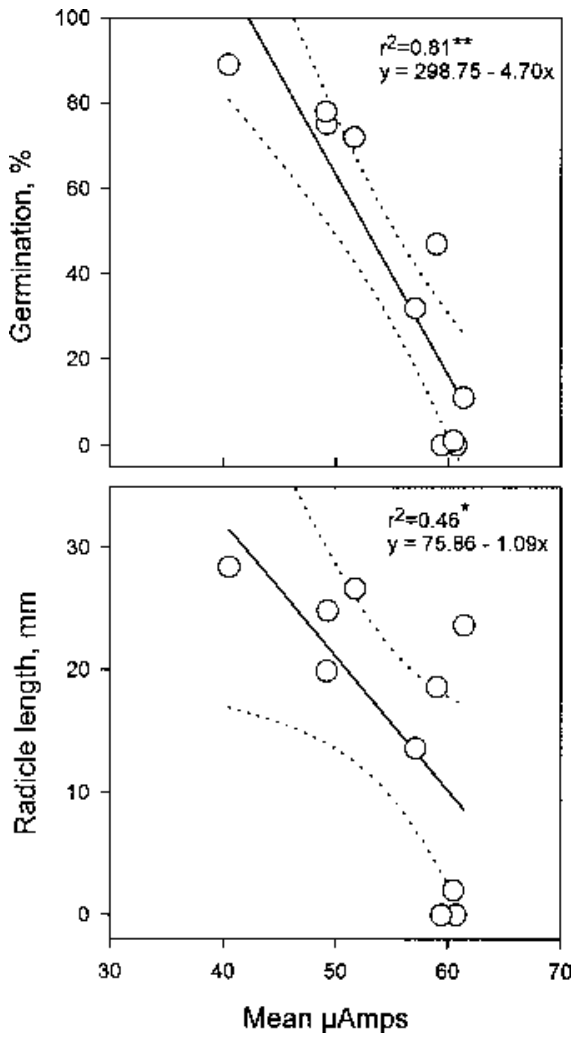

Fig. 5. Prediction of maize germination and radicle length by mean current value ( $\mu$ Amps) observed at 5-h imbibition; $95 \%$ confidence bands. ${ }^{*, * *}$ Significant at $P \leq 0.05$ and 0.01 , respectively.

tion and $52 \%$ of the variability in radicle length (Fig. 6). The prediction model presented for percent germination does not account for the contribution of seed lot interaction with the index for germination data (Table 3 ), which was significant according to the ANOVA results. Nevertheless, separating the two seed lots (Fig. 6) for regression simply yields different slopes of the same trend, but the correlation coefficients for each regression were increased and accounted for $90 \%$ and $99 \%$ of the variability in germination for lots $88-1 \mathrm{~d}$ and $88-2 \mathrm{i}$, respectively. However, only one regression is presented in Fig. 6 for both seed lots.

Arithmetic means, medians, and modes of frequency distributions generally are used to describe populations and may qualify as seed quality indicators. Means are strongly affected by extreme values and all three values are measures of distribution location, whereas IS is not associated with distribution location and therefore has wider application (Moore et al., 1988). IS summarizes leakage data (i.e., the larger the IS value the less variation among individual seed quality and the higher the seed lot quality); thus, IS may be a useful predictor of seed-to-seed variability in germination. Because IS is inversely related to seed quality, the reciprocal of IS measures seed-to-seed leachate variability in a positive way. IS may provide a description of the state of deterioration of a seed sample.

Wilson (1992) suggested that the IS method overlooks the underlying biology that leaky seeds are bad; however, IS accounts for the 


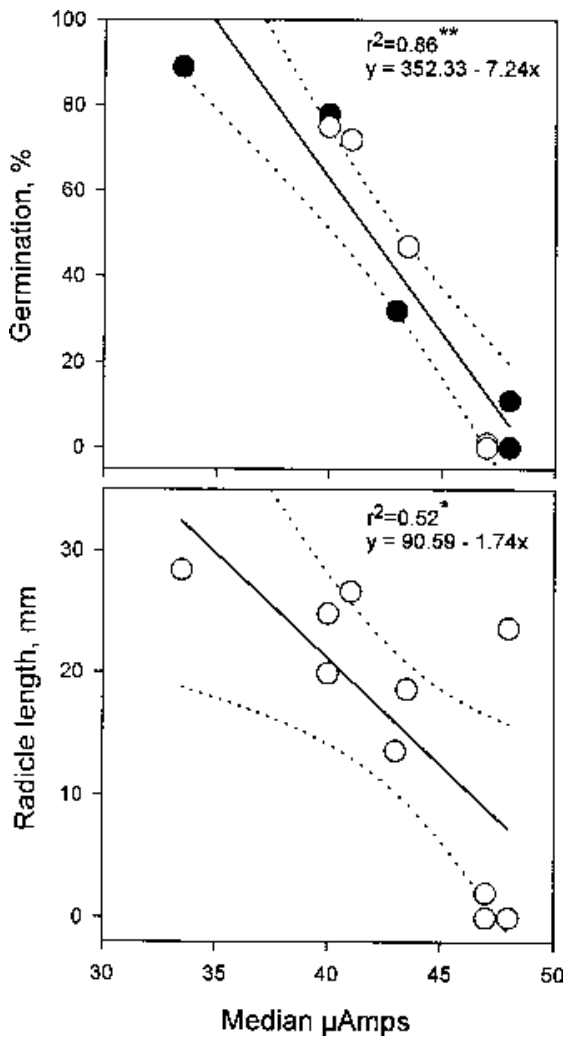

Fig. 6. Prediction of maize germination and radicle length by median current value, $\mu$ Amps, observed at 5-h imbibition; $95 \%$ confidence bands. *,**Significant at $P \leq 0.05$ and 0.01 , respectively. Analysis of variance indicated that seed lot should be represented separately [(O) lot 88-1d, (○) lot 88-2i].

shape of the frequency distribution that includes all of the seeds in the sample, good or bad. Low-quality seed exhibit not only poor emergence, but also sporadic or variable emergence, and we have shown that low-quality seed exhibit greater EC variability. The frequency distributions (i.e., the derivative of the CFD) became broader, decreased in peak height, and generally shifted to higher values with increasing seed deterioration (data not shown). This result corroborates the frequency histograms of Furman et al. (1987) and McDonald and Wilson (1980). As the CFD broadens over the $\mu$ Amp axis due to increased seed-to-seed variability (a reflection of seed deterioration), IS decreases, but the measure of variability (1/IS) increases. Measures of central tendency disregard biology; hence, it is important to evaluate seed quality from frequency distribution histograms, population statistics that describe the shape of the distribution, or indices created from these population statistics that may take the mean value and SD into account.

ILR was derived by fitting Johnson's (1987) version of the rectangular hyperbola to $\mu \mathrm{Amp}$ vs. soak time data (Fig. 2) for each 100-seed test and calculating ILR as $1 / \mathrm{m}$, Eq. [2]. The rectangular hyperbola has biological rationale; it is frequently used in enzyme kinetics (Thornley and Johnson, 1990) and fits the leakage data well (Fig. 2). However, there was neither a correlation between ILR and viabil- ity or radicle length nor any significant interaction between seed lot and ILR (Table 4). The most rapid electrolyte leakage rate that occurs on first contact with water is theoretically quantified by ILR. Nevertheless, this is a highly variable state of imbibition, conceivably varying dramatically from seed to seed. Duke et al. (1983) suggested that electrolyte leakage, as a function of seed hydration, is a passive process during the early phase of imbibition before the membranes have reorganized and regained selective permeability. Keys (1982) interpreted the initial phase of rapid electrolyte leakage, which is nonlinear, as physicalnot physiological and, therefore, not indicative of seed quality. Seed quality was not predicted by ILR, which is a theoretical maximum leakage rate at the zero soak time. Furthermore, surface contamination with electrolytes may have interfered with use of this index. Seeds were not surface sterilized because this would have induced leakage, and our interest was to obtain the rate of electrolyte

Table 3. Analysis of variance for linear regression of the median $\mu$ Amp value at 5 -h imbibition on percent germination and radicle length.

\begin{tabular}{lcccc}
\hline \hline Source & df & Mean square & F statistic & Probability \\
\hline & & \% Germination & & \\
Median $\mu$ Amp & 1 & 10176 & 88.12 & 0.00 \\
Seed lot & 1 & 82.24 & 0.71 & 0.43 \\
Seed lot $\times$ median & 1 & 815.23 & 7.06 & 0.04 \\
Error & 6 & 115.48 & & \\
Total & 9 & & & 0.02 \\
& & Radicle length & & 0.90 \\
Median $\mu$ Amp & 1 & 586.11 & 0.91 & \\
Seed lot & 1 & 0.97 & 0.02 & \\
Seed lot $\times$ median & 1 & 226.93 & 4.20 & \\
Error & 6 & 53.74 & & \\
Total & 9 & \% Germination & & \\
& & 10176.14 & 51.19 & \\
Model & 1 & 198.79 & & 0.02 \\
Error & 8 & & & \\
Total & 9 & Radicle length & & \\
& & 586.11 & & \\
Model & 1 & 68.79 & & \\
Error & 8 & & & \\
Total & 9 & & & \\
\hline
\end{tabular}

Table 4. Analysis of variance for linear regression of the initial leach rate (ILR) index on percent germination and radicle length.

\begin{tabular}{|c|c|c|c|c|}
\hline Source & $\mathrm{df}$ & Mean square & F statistic & Probability \\
\hline \multicolumn{5}{|c|}{$\%$ Germination } \\
\hline ILR & 1 & 69.64 & 0.05 & 0.83 \\
\hline Seed lot & 1 & 0.27 & 0.00 & 0.99 \\
\hline Seed lot $\times$ ILR & 1 & 3064.07 & 2.13 & 0.20 \\
\hline Error & 6 & 1438.75 & & \\
\hline Total & 9 & & & \\
\hline \multicolumn{5}{|c|}{ Radicle length } \\
\hline ILR & 1 & 2.74 & 0.02 & 0.90 \\
\hline Seed lot & 1 & 17.04 & 0.11 & 0.75 \\
\hline Seed lot $\times$ ILR & 1 & 202.03 & 1.32 & 0.29 \\
\hline Error & 6 & 152.44 & & \\
\hline Total & 9 & & & \\
\hline \multicolumn{5}{|c|}{$\%$ Germination } \\
\hline Model & 1 & 69.64 & 0.05 & 0.83 \\
\hline Error & 8 & 1462.11 & & \\
\hline Total & 9 & & & \\
\hline \multicolumn{5}{|c|}{ Radicle length } \\
\hline Model & 1 & 2.74 & 0.02 & 0.89 \\
\hline Error & 8 & 141.71 & & \\
\hline Total & 9 & & & \\
\hline
\end{tabular}

leakage from the seeds on their initial contact with water.

There was no correlation between either percent germination or radicle length and ALR. The Richards regression (Fig. 3) did not fit $\mu$ Amp vs. soak time data as well as the rectangular hyperbolic regression (Fig. 2), and this may account for the poor predicting capacity of this index. Also, ALR approximates an average absolute rate (Causton et al., 1978), in this case an average leakage rate over the entire soak period, taking into account the initially rapid phase and the slower gradual phase during which an asymptote is approached. These two phases of electrolyte leakage would seem to have fundamental physiological differences. We observed the initial leakage rate to be unstable, as did Duke et al. (1983). Kuo (1986) suggested that once solute leakage has slowed after the early leachate was removed, an effective seed-quality prediction could be made. This approach may improve the use of ALR as a seed quality 
Table 5. Analysis of variance for linear regression of the average leach rate index (LRI) on percent germination and radicle length.

\begin{tabular}{|c|c|c|c|c|}
\hline Source & df & Mean square & F statistic & Probability \\
\hline \multicolumn{5}{|c|}{$\%$ Germination } \\
\hline ALR & 1 & 305.44 & 0.32 & 0.59 \\
\hline Seed lot & 1 & 474.40 & 0.50 & 0.51 \\
\hline Seed lot $\times$ ALR & 1 & 5315.58 & 5.62 & 0.06 \\
\hline Error & 6 & 945.18 & & \\
\hline Total & 9 & & & \\
\hline \multicolumn{5}{|c|}{ Radicle length } \\
\hline ALR & 1 & 54.49 & 0.39 & 0.56 \\
\hline Seed lot & 1 & 149.42 & 1.07 & 0.34 \\
\hline Seed lot $\times$ ALR & 1 & 92.40 & 0.66 & 0.45 \\
\hline Error & 6 & 140.02 & & \\
\hline Total & 9 & & & \\
\hline \multicolumn{5}{|c|}{$\%$ Germination } \\
\hline Model & 1 & 305.44 & 0.21 & 0.66 \\
\hline Error & 8 & 1432.63 & & \\
\hline Total & 9 & & & \\
\hline \multicolumn{5}{|c|}{ Radicle length } \\
\hline Model & 1 & 54.49 & 0.40 & 0.54 \\
\hline Error & 8 & 135.24 & & \\
\hline Total & 9 & & & \\
\hline
\end{tabular}

index. The prediction model presented for percent germination does not account for the contribution of seed lot interaction with the index for germination data (Table 5), which was significant according to the ANOVA results. Nevertheless, separating the two seed lots for the purposes of regression simply yields different slopes of the same trend. The correlation coefficients for each regression increased and accounted for $29 \%$ and $71 \%$ of the variability in germination for lots $88-1 d$ and $88-2 \mathrm{i}$, respectively; however, neither was significant.

Five candidate indices were used for predicting seed quality using EC data. Two of these were measures of central tendency or location on the $\mu$ Amp axis (mean and median $\mu$ Amps), and three (IS, initial leach rate, and average leach rate) were secondary parameters derived from two functions nonlinear in their parameters. The mean and median $\mu \mathrm{Amp}$ values at 5-h imbibition were capable of predicting maize seed quality, accounting for $>80 \%$ of the variability in germination. However, central tendency measures disregard the underlying biology; hence, it is important to evaluate seed quality from frequency distribution (i.e., population statistics that describe the shape of the distribution). IS was the only secondary parameter capable of predicting maize seed quality, accounting for $91 \%$ of the variability in germination. IS, the median $\mu$ Amp value, and the mean $\mu$ Amp value were the best seed-quality indicators; however, IS can be thought of as a curve-shape constanta direct measure (1/IS) of seed-to-seed variation in electrolyte leakage-thus providing biological rationale for its use. IS tests based on electrolyte leakage are fast and simple and as such may provide the seed industry with an alternative to the standard germination test, reducing time and labor costs. Also, this method would allow seed laboratories to monitor deterioration of the same seed sample over time, granted the testing (i.e., soak time) is brief enough. The nonlinear regression model for deriving initial leach rate fits the data well; however, the derived index relies on unstable initial leakage rates and results in poor prediction capacity. The nonlinear regression model for calculating average leach rate did not fit the data well and is likely the reason for the poor prediction capacity of this index. In all of the linear regression prediction models, there were better correlations when the response was germination rather than radicle length, possibly because of artificial aging. Invigoration (Savino et al., 1979), which was observed in the EC samples, may have interfered because of artificial aging. Nonaged or naturally aged seed should be tested to determine whether this is true and to verify the IS method of noninvasive seed quality determination.

\section{Literature Cited}

Association of Official Seed Analysts. 1988. Rules

Berry, G.J., R.J. Cawood, and R.G. Flood. 1988. Curve fitting of germination data using the Richards function. Plant, Cell \& Environ. 11:183-188.

Bondie, J., T. Limperis, and W.C. Steere. 1979. The automatic seed analyzer, p. 72-75. In: J.M. Brown (ed.). Proc. 1979 Beltwide Cotton Production-Mechanization Conf. Phoenix, Ariz., 7-11 Jan. 1979.

Bruggink, H. 1989. Evaluation and improvement of vigour test methods. 1. An alternative procedure for the controlled deterioration test. Acta Hort. 253:143-151.

Causton, D.R. 1969. A computer program for fitting the Richards function. Biometrics 25:401-409.

Causton, D.R., C.O. Elias, and P. Hadley. 1978. Biometrical studies of plant growth. I. The Richards function, and it's application in analyzing the effects of temperature on leaf growth. Plant, Cell \& Environ. 1:163-184.

Ching, T.M. and I. Schoolcraft. 1968. Physiological and chemical differences in aged seeds. Crop Sci. 8:407-409.

Duke, S.H., G. Kakefuda, and T.M. Harvey. 1983. Differential leakage of intracellular substances from imbibing soybean seeds. Plant Physiol. 72:919-924.

France, J. and J.H.M. Thornley. 1984. Mathematical models in agriculture. Butterworths, London. Furman, K.C., L.W. Woodstock, and T. Solomos. for testing seeds. J. Seed Technol. 12(3):1-109.
1987. Interfacing the ASAC- 1000 seed analyzer with an IBM-PC microcomputer using the basic program ASACSTAT. J. Seed Technol. 11(1):79-87.

Hepburn, H.A., A.A. Powell, and S. Matthews. 1984. Problems associated with the routine application of electrical conductivity measurements of individual seeds in the germination testing of peas and soyabeans. Seed Sci. Technol. 12:403413.

Johnson, I.R. 1987. Models of respiration, p. 89108. In: K. Wisiol and J.D. Hesketh (eds.). Plant growth modeling for resource management. vol. 2. CRC Press, Boca Raton, Fla.

Keys, R.D. 1982. Dynamic conductometric analysis of peanut (Arachis hypogaea L.) seed leachate using the CASAS (computerized automated seed analysis system). J. Seed Technol. 7(1):36-59.

Kuo, W.J.H. 1986. Improved electrical conductivity test as a method predicting viability of rice seeds. J. Agr. Assn. China 136:1-5.

Matthews, S. and W.T. Bradnock. 1968. Relationship between seed exudation and field emergence in peas and French beans. Hort. Res. 8:89-93.

McDonald, M.B., Jr., and D.O. Wilson. 1979. An assessment of the standardization and ability of the ASA-610 to rapidly predict potential soybean germination. J. Seed Technol. 4(2):1-11.

McDonald, M.B., Jr., and D.O. Wilson. 1980. ASA610 ability to detect changes in soybean seed quality. J. Seed Technol. 5(1):56-66.

Moore, F.D., III, P.A. Jolliffe, P.C. Stanwood, and E.E. Roos. 1988. Use of the Richards function to interpret single seed conductivity data. HortScience 23:396-398.

Mullet, J.H. and R.I. Wilkinson. 1979. The relationship between amounts of electrolyte lost on leaching seeds of Pisum sativum and some parameters of plant growth. Seed Sci. Technol. 7:393-398.

Nath, S.R., H.K. Cahn, F.D. Moore, III, and E.E. Roos. 1990. Seed quality and the Richards function: A user's program. Colorado Agr. Expt. Sta. Tech. Bul. TB90-2.

Nath, S.R., F.D. Moore, and K.A. Garrett. 1993. User's manual for a portable UNIX-based computer program to delineate growth phases using the Richards function. Colorado Agr. Expt. Sta. Tech. Bul. TB93-1.

O'Brien, F.E.M. 1948. The control of humidity by saturated salt solutions. J. Sci. Instruments \& Physics Industry 25:73-76.

Pandy, D.K. 1988. A rapid method for the prediction of germinability of French beans. Ann. Applied Biol. 113:443-446.

Parish, D.J. and A.C. Leopold. 1978. On the mechanism of aging in soybean seeds. Plant Physiol. 61:365-368.

Powell, A.A. 1986. Cell membranes and seed leachate conductivity in relation to the quality of seed for sowing. J. Seed Technol. 10(2):81-100.

Richards, F.J. 1959. A flexible growth function for empirical use. J. Expt. Bot. 10:290-300.

Savino, G., P.M. Haigh, and P. De Leo. 1979. Effects of presoaking upon seed vigor and viability during storage. Seed Sci. Technol. 7:5764.

Steere, W.C., W.C. Levengood, and J.M. Bondie. 1981. An electronic analyzer for evaluating seed germination and vigor. Seed Sci. Technol. 9:567576.

Thornley, J.H.M. and I.R. Johnson. 1990. Plant and crop modelling. A mathematical approach to plant and crop physiology. Oxford Univ. Press, New York.

Wilson, D.O., Jr. 1992. A unified approach to interpretation of single seed conductivity data. Seed Sci. Technol. 20:155-163. 